\title{
Modification of alternative additives and their effect on the rubber properties
}

\author{
Darina Ondrušová ${ }^{1, *}$, Slavomíra Božeková ${ }^{1}$, Lenka Buňová $^{1}$, Mariana Pajtášová ${ }^{1}$ \\ Ivan Labaj ${ }^{1}$, Andrej Dubec ${ }^{1}$, Juliána Vršková ${ }^{1}$ \\ ${ }^{1}$ Alexander Dubček University of Trenčín, Faculty of Industrial Technologies in Púchov, I. Krasku \\ 941/30, 02001 Púchov, Slovakia; darina.ondrusova@fpt.tnuni.sk
}

\begin{abstract}
The present paper deals with a targeted modification of two kinds of alternative additives - waste from glass production and natural mineral filler and explores their effect on the properties of polymeric materials. In the function of first alternative filler was used sludge from weighing the ingredients of glass batch in the glass production. The second used was natural aluminosilicate material based on zeolite (clinoptilolite). These alternative fillers have been modified in order to increase its efficiency, using the silanes: 3-aminopropyl-triethoxysilane, bis(triethoxysilyl)propyl-tetrasulfide and 3-(triethoxysilyl)propyl-methacrylate. In the case of alternative filler based on zeolite the influence of silanization conditions on the filler efficiency have been also studied. Prepared modified fillers were mixed into rubber compounds as partial replacement of commonly used filler - carbon black. The influence of prepared fillers on rheology and curing characteristics of rubber compounds and also on physical and mechanical properties of vulcanizates has been studied. Obtained results of measured characteristics of polymeric systems containing prepared alternative fillers were compared with the results obtained in the case of reference rubber compound with a commertially used filler - carbon black.
\end{abstract}

Keywords: rubber, alternative filler, zeolite, glass waste, silanization

\section{Introduction}

The application of inorganic materials into organic polymers is one of the usual ways to improve up of physical and mechanical properties of polymers specifically hardness, tensile strength, modulus [1]. Composite materials show generally better properties than pure and homogeneous materials. The positive changes have been observed at very low concentration of inorganic mineral component in polymers [1,2]. In the rubber industry the fillers based on $\mathrm{SiO}_{2}$, calcium carbonate or glass are frequently used and also mineral fillers based on clay minerals such as kaolin [3-5]. Alternative filler used in present experiments comes from the weighing process of raw materials in glass production, where creates the waste in a sludge form.

\footnotetext{
*Corresponding author: darina.ondrusova@fpt.tnuni.sk

Reviewers: František Nový, Eva Tillová
} 
The chemical composition of this alternative filler is similar to the chemical composition of kaolin, which is commonly used in rubber industry. Chemical composition of kaolin contains oxides like $\mathrm{SiO}_{2}, \mathrm{Al}_{2} \mathrm{O}_{3}, \mathrm{CaO}$ and other trace elements, while the total content of $\mathrm{SiO}_{2}$ in kaolin is $73,45 \% \mathrm{SiO}_{2}[6] \cdot \mathrm{SiO}_{2}$ and $\mathrm{CaO}$ also are a major components of this studied waste from glass production, therefore it has been applied into polymer materials in the function of filler.

The other kind of additivum used was natural mineral material - zeolite. Natural zeolites form a group of aluminosilicatenanoporous materials with the special porous structure allowing lots of practical applications as an ion-exchange, adsorbent, material for reversible hydratation and dehydratation and also as ecological nanofiller in polymeric materials [3].

The best known type of zeolite is clinoptilolite. Its structure (Fig.1) is based on treedimensional frameworks composed of tetrahedral $\mathrm{SiO}_{4}$ and $\mathrm{AlO}_{4}$ units, which are connected by shared oxygen atoms [4,5].

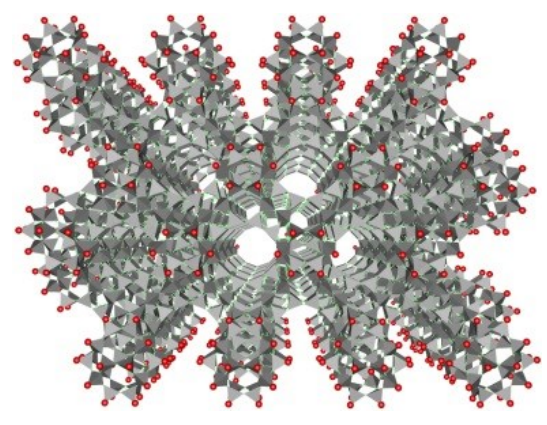

Fig. 1. 3D Crystalline Grid of Clinoptilolite

Surface modification of inactive mineral fillers (for example zeolites, clay minerals), has attracted much attention because the obtained products exhibit properties suitable for many materials and environmental applications [7]. Modification is generally considered to be an attractive and effective method to render inorganic mineral filler particles more compatible with polymeric matrix [8-10]. As the compatibility between fillers and polymers is low, a reduction of the polarity differences is required. This can be done by silane coupling agents such as (3-Aminopropyl)triethoxysilane, which is capable of acting with the filler surface and the polymer, and is commonly applied in silica-filled rubber $[11,12]$.

The present paper deals with the modification of two kinds of alternative additives based on waste from glass production and on zeolite clinoptilolite by silanization process and application of prepared modified forms into polymeric materials in the function of fillers.

\section{Experimental}

\subsection{Preparation and modification of alternative additives}

\subsubsection{Preparation of alternative fillers based on the glass waste}

The unmodified alternative filler - sludge was dried at the temperature of $105 \pm 5{ }^{\circ} \mathrm{C}$ to constant weight. For experiments the alternative filler with a particle size $<25 \mu \mathrm{m}$ was used. 
The unmodified sample of alternative filler was analysed using X-ray fluorescence spectrometer S8 TIGER for the analysis of light elements. Results of chemical analysis of sludge sample studied are given in Table 1.

Table 1. Chemical composition of unmodified alternative filler - sludge

\begin{tabular}{|l|c|c|c|c|c|c|c|c|c|c|c|c|c|c|}
\hline Oxide & $\mathrm{SiO}_{2}$ & $\mathrm{CaO}$ & $\mathrm{Al}_{2} \mathrm{O}_{3}$ & $\mathrm{BaO}$ & $\mathrm{Na}_{2} \mathrm{O}$ & $\mathrm{K}_{2} \mathrm{O}$ & $\mathrm{Sb}_{2} \mathrm{O}_{3}$ & $\mathrm{Fe}_{2} \mathrm{O}_{3}$ & $\mathrm{TiO}_{2}$ & $\mathrm{MgO}$ & $\mathrm{Cr}_{2} \mathrm{O}_{3}$ & $\mathrm{Er}_{2} \mathrm{O}_{3}$ & $\mathrm{Cl}$ & $\mathrm{SO}_{3}$ \\
\hline $\begin{array}{l}\text { Mass } \\
(\%)\end{array}$ & 73.09 & 15.14 & 3.95 & 2.68 & 1.32 & 1.24 & 0.93 & 0.67 & 0.19 & 0.16 & 0.1 & 0.1 & 0.07 & 0.06 \\
\hline
\end{tabular}

The results of chemical analysis have confirmed that main components of studied sludge are $\mathrm{SiO}_{2}$ and $\mathrm{CaO}$, what is a positive precondition for its further application in the function of filler. Subsequently the sample of alternative filler was modified with three following silanes:

- (3-Aminopropyl)triethoxysilane (A),

- bis3-(Triethoxysilyl)propyl-tetrasulfide (E),

- 3-(Trimethoxysilyl)propyl-methacrylate (M).

The modification was carried out using 3 weight parts of modifying agent per 100 weight parts of filler according to the standard procedures [7]. To ensure homogeneous cover of alternative filler surface, the modification was performed in a mixture of water and ethanol under the same conditions using three different silane agents. Appropriate amounts of alternative filler, modifying agent and solvent were stirred for 2 hours and obtained modified forms of fillers after filtration were dried (Fig. 2). For further experiments three prepared modified alternative fillers with a particle size $<25 \mu \mathrm{m}$ were used.



Fig. 2. Preparation of modified alternative fillers based on glass waste

\subsubsection{Preparation of alternative fillers based on clinoptilolite}

The clinoptilolite with a particle size $<7 \mu \mathrm{m}$ was used for the experiments. Two series of the silanized samples of clinoptilolite were prepared by hydrolysis of (3Aminopropyl)triethoxysilane (APTES) in the mixture of ethanol / water (90:10). The clinoptilolite with a particle size $<7 \mu \mathrm{m}$ was finally added into the mixture. The first series of three samples of silanisedclinoptilolite were stirred at $250 \mathrm{rpm}$ in a water bath with a temperature of $50^{\circ} \mathrm{C}$. The second set of samples was stirred at $250 \mathrm{rpm}$ at room temperature. Stirring times of samples were 1, 2 and 3 hours. The separated modified samples of clinoptilolite were dried in dryer for 60 minutes at temperature $110^{\circ} \mathrm{C}$. 
Six samples of the modified zeolite fillers were prepared by silanization under various conditions (Table 2).

Table 2. Labeling of prepared silanized forms of clinoptilolite

\begin{tabular}{|c|l|}
\hline Samples & \multicolumn{1}{|c|}{ Characteristics } \\
\hline $\mathbf{2 ~ Z 1 H}$ & cliloptilolitesilanized 1 hour at $50^{\circ} \mathrm{C}$ \\
\hline $\mathbf{3 ~ Z 2 H}$ & cliloptilolitesilanized 2 hours at $50^{\circ} \mathrm{C}$ \\
\hline $\mathbf{4 ~ Z 3 H}$ & cliloptilolitesilanized 3 hours at $50^{\circ} \mathrm{C}$ \\
\hline $\mathbf{5} \mathbf{~ N 1 H}$ & cliloptilolitesilanized 1 hour at room temperature \\
\hline $\mathbf{6} \mathbf{~ N 2 H}$ & cliloptilolitesilanized 2 hours at room temperature \\
\hline $\mathbf{7} \mathbf{~ N 3 H}$ & cliloptilolitesilanized 3 hours at room temperature \\
\hline
\end{tabular}

\subsection{Preparation of rubber compounds}

\subsubsection{Rubber compounds with alternative fillers based on the glass waste}

The four model rubber compounds were prepared by two-step mixing in laboratory mixer Brabender in the standard way [13]. Composition of tread rubber compounds were different in type of filler. The carbon black was replaced by unmodified and modified alternative filler in a ratio of 2:1. Labelingof samples and used types of fillers are shown in the Table 3 .

Table 3. Labeling of samples and dosage of fillers based on glass waste

\begin{tabular}{|l|l|l|}
\hline Samples & Filler & Ratio of fillers \\
\hline BK 2:1 & Carbon black + unmodified alternative filler & $2: 1$ \\
\hline BKA 2:1 & Carbon black + modified alternative filler by silane agent A & $2: 1$ \\
\hline BKE 2:1 & Carbon black + modified alternative filler by silane agent E & $2: 1$ \\
\hline BKM 2:1 & Carbon black + modified alternative filler by silane agent M & $2: 1$ \\
\hline
\end{tabular}

Temperature $145{ }^{\circ} \mathrm{C}$ at the 50 rotations per second was the conditions relating to the first mixing step. In the second mixing step, curing agent (sulfur) and accelerator were added to the rubber compounds. Temperature $100^{\circ} \mathrm{C}$ at the 50 rotations per second was the condition relating to the second mixing step. After mixing process, rubber compounds were left for 24 hours.

\subsubsection{Rubber compounds with alternative fillers based on clinoptilolite}

The eight model rubber compounds were prepared by two-step mixing in laboratory mixer Plastograph-Brabender in the standard way $[13,14]$. The first step of mixing was carried out at the temperature of $130{ }^{\circ} \mathrm{C}$ and a rate of pinions rotation was $50 \mathrm{rpm}$. The activator of vulcanization $(\mathrm{ZnO})$ together with the fillers - carbon black, natural clinoptilolite (PZ) or silanized forms of clinoptilolite (as a replacement forcarbon black) and the natural rubber were used. In the second step which was carried out at the temperature $110{ }^{\circ} \mathrm{C}$ sulphur in a function of vulcanization agent and accelerator of vulcanization were added [13].After mixing process, rubber compounds were left for 24 hours. The fillers content in prepared model rubber compounds with the labeling of samples are indicated in Table 4. 
Table 4. Fillers content in prepared model rubber compounds (in phr) with the labeling of samples

\begin{tabular}{|c|c|c|c|c|c|c|c|c|}
\hline Sample/Filler & $\begin{array}{c}\text { Carbon } \\
\text { black }\end{array}$ & $\mathbf{P Z}$ & $2 \mathrm{Z1H}$ & $3 \mathrm{Z2H}$ & $4 \mathrm{Z3H}$ & $5 \mathrm{~N} 1 \mathrm{H}$ & $6 \mathrm{~N} 2 \mathrm{H}$ & $7 \mathrm{N3H}$ \\
\hline$\check{\mathbf{S}}$ & 70 & - & - & - & - & - & - & - \\
\hline 1PZ & 25 & 45 & - & - & - & - & - & - \\
\hline $2 \mathrm{Z1H}$ & 25 & - & 45 & - & - & - & - & - \\
\hline $3 \mathrm{Z2H}$ & 25 & - & - & 45 & & - & - & - \\
\hline $4 \mathrm{Z3H}$ & 25 & - & - & - & 45 & - & - & - \\
\hline $5 \mathrm{N1H}$ & 25 & - & - & - & - & 45 & - & - \\
\hline $6 \mathrm{~N} 2 \mathrm{H}$ & 25 & - & - & - & - & - & 45 & - \\
\hline $7 \mathrm{~N} 3 \mathrm{H}$ & 25 & - & - & - & - & - & - & 45 \\
\hline
\end{tabular}

${ }^{*} \mathrm{phr}=$ parts per hundred rubber

\subsection{Study of Rheology and Curing characteristics}

The rheological properties and curing characteristic $\left(M_{L}, M_{H}, t_{s 2}, t_{90}, R_{v}\right)$ of rubber compounds prepared were measured using Vulcameter Monsanto 100 at the temperature of $150{ }^{\circ} \mathrm{C}$ during $60 \mathrm{~min}$, according to specifications in STN [15]. Obtained values of rheological and curing characteristics of rubber compounds containing modified and

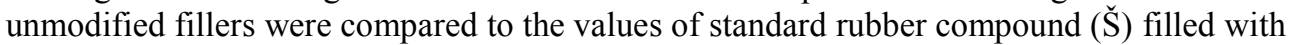
carbon black and all obtained values were also compared between themselves.

\subsection{Study of Physical and Mechanical properties}

The physical and mechanical properties of vulcanizates prepared were determined by help of tearing machine INSTRON according to STN [16]. The tensile strength and elongation at break were evaluated properties. Hardness of vulcanizate was measured by hardness tester IRHD according to STN [17]. The measured values of physical and mechanical properties of vulcanizates were compared with the values of standard rubber compound ( $\breve{\mathrm{S}}$ ) with carbon black filler and were compared between themselves too.

\subsection{Microstructural SEM analysis}

Microstructure of fillers and vulcanizates was studied using Scanning Electron Microscop TESCAN VEGA 3. The microanalysis was focused on the evaluation of topography and microrelief of filler particles using detector in a high vacuum, which is operating in the secondary electrons mode. The filler particles were fixed on adhesive carbon discs that provide conductivity between the sample and the sample stage. For optimal microstructure evaluation the surface of filler particles was metal plated using conductive layer based on the elements $\mathrm{Au}$ and $\mathrm{Pd}$. This layer is also formed under high vacuum and under an argon atmosphere. Thanks to such sample preparation conditions, it was possible to apply the maximum incandescent cathode voltage $30 \mathrm{kV}$, which allows to get greater sharpness images from the area as well as a short distance of analyzed area from the lens. 


\section{Results and discussion}

\subsection{Effect of additives on Rheology and Curing characteristics}

\subsubsection{Rubber compounds with alternative fillers based on glass waste}

The results from the study of rheological properties and curing characteristic $\left(\mathrm{M}_{\mathrm{L}}, \mathrm{M}_{\mathrm{H}}, \mathrm{t}_{\mathrm{s} 2}\right.$, $t_{90}, R_{v}$ ) are shown in Figs. $3-5$. The minimum torque values $M_{L}$ (Fig. 3) of all rubber compounds prepared were comparable.

In contrast, the maximum torque $\mathrm{M}_{\mathrm{L}}$ values of rubber compounds with modified alternative fillers are higher than value of rubber compound with unmodified alternative filler (Fig. 4). The higher values of maximum torque show higher stiffness at the end of the vulcanization and they also show higher viscosity.

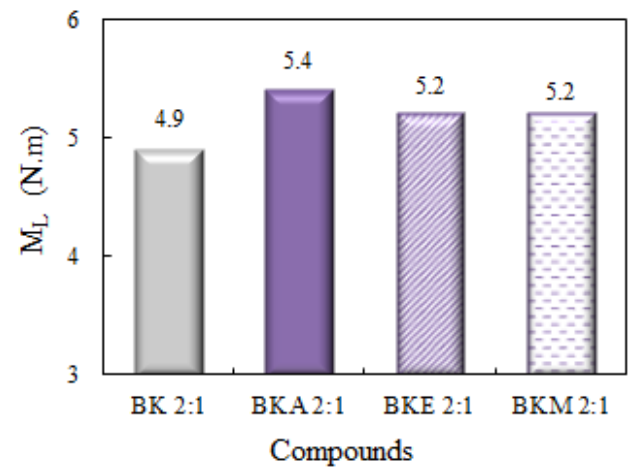

Fig. 3. Values of minimum torque $\mathrm{M}_{\mathrm{L}}$ of rubber compounds

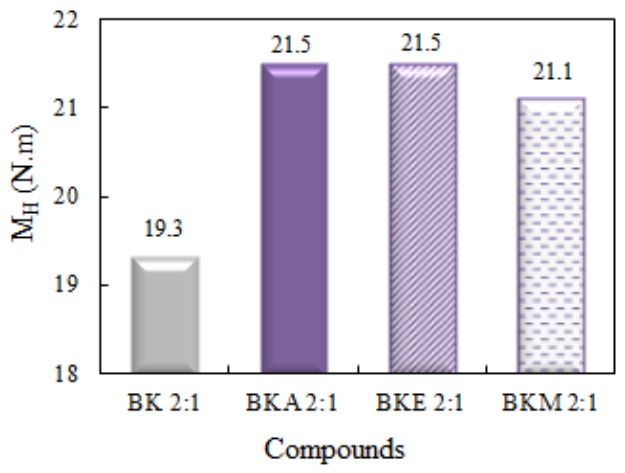

Fig. 4. Values of maximum torque $\mathrm{M}_{\mathrm{H}}$ of rubber compounds

Modification of filler did not have significant influence on the start time of vulcanization. On the other hand, from Fig.5, it can be seen that the blends samples containing modified alternative fillers showed a shortening the optimum vulcanization time compared to the blend sample BK 2:1 filled with unmodified filler. 


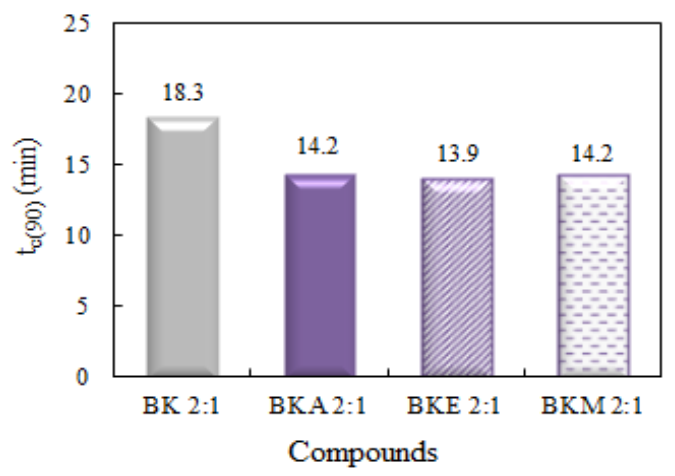

Fig. 5. Values of optimum time of vulcanization $t_{90}$ of rubber compounds

This is confirmed in a positive impact of alternative filler modifications with silanes. This can also have a positive impact on the overall shortening of the production process. Shortening the optimum vulcanization time was reflected also in the increase in cure rate coefficient $R_{v}$ (Fig. 6) in the cases of blends samples BKA 2:1, BKE 2:1 and BKM 2:1, containing alternative fillers modified with silanes in comparison with the rubber compound sample BK 2:1 filled with unmodified alternative filler .

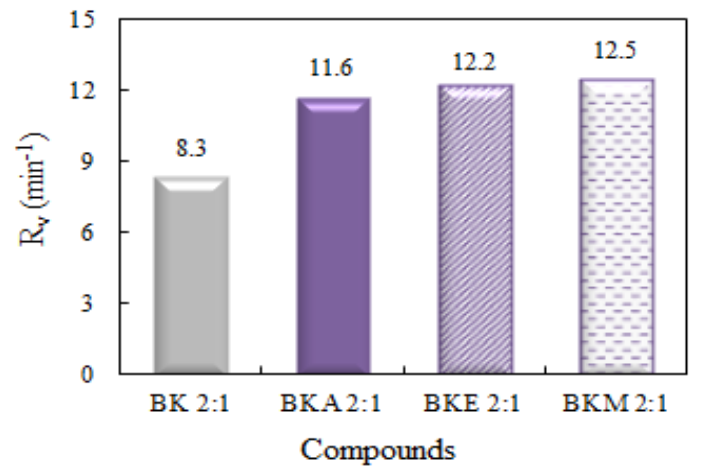

Fig. 6. Values of cure rate coefficient $R_{v}$ of rubber compounds

\subsubsection{Rubber compounds with alternative fillers based on clinoptilolite}

The obtained values of rheological and curing characteristics $\left(\mathrm{M}_{\mathrm{L}}, \mathrm{M}_{\mathrm{H}}, \mathrm{t}_{\mathrm{s} 2}, \mathrm{t}_{\mathrm{c} 90}, \mathrm{R}_{\mathrm{v}}\right)$ are shown in Figs. 7 - 9. From the values of scorch of time $t_{s 2}$ (Fig. 7) it is observed that the highest $t_{\mathrm{S} 2}$ value showed sample 1PZ. A decrease of scorch of time values in the cases of samples 2-7,in comparison with a blend containing an unmodified zeolite filler, is due to modification of silanisation. 




Fig. 7. Values of Scorch of time $t_{\mathrm{s} 2}$ of rubber compounds

The rubber compounds $2 \mathrm{Z} 1 \mathrm{H}, 4 \mathrm{Z} 3 \mathrm{H}, 6 \mathrm{~N} 2 \mathrm{H}$ and $7 \mathrm{~N} 3 \mathrm{H}$ that were silanized under various conditions, showed a slight increase in scorch of time values compared to standard blend. That might be good in terms of the optimal course of rubber compounds processing. All rubber compounds containing modified silanized forms of filler based on clinoptilolite showed the scorch of time values comparable to standard rubber blend.

The same trend of a positive influence of silanization process has also been observed in the case of the obtained values of optimum of vulcanization (Fig. 8). Although, different conditions of silanisation of filler did not have significant influence on reology and curing characteristics, the positive influence of silanization of clinoptilolite filler is considerable.

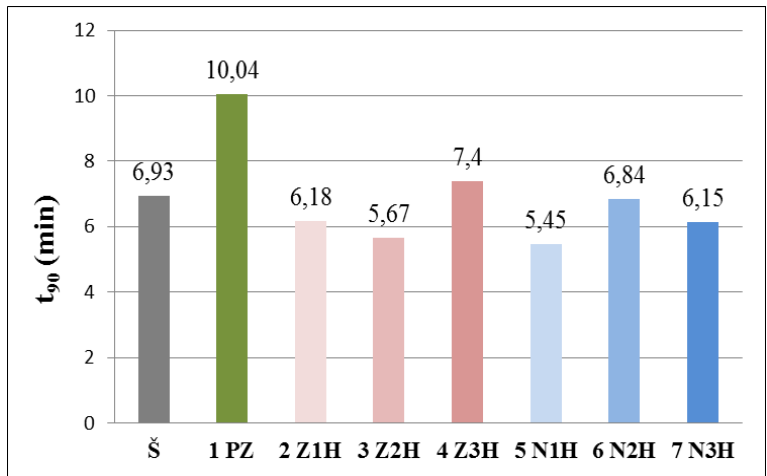

Fig. 8. Values of optimum time of vulcanization $t_{90}$ of rubber compounds

From the measured values of coefficient of cure rate (Fig. 9) it can be concluded, that the modification of fillers had a positive effect on the cure rate. Rubber blends 2-7 containing modified fillers by silanization under various conditions show values of $\mathrm{Rv}$ higher than mixture with standard filler carbon black. The lowest Rv value showed the mixture containing unmodified clinoptilolite 1PZ. Thus, the use of silane APTES showed a positive effect on the activity of all components in the rubber blends containing a modified zeolite filler. 


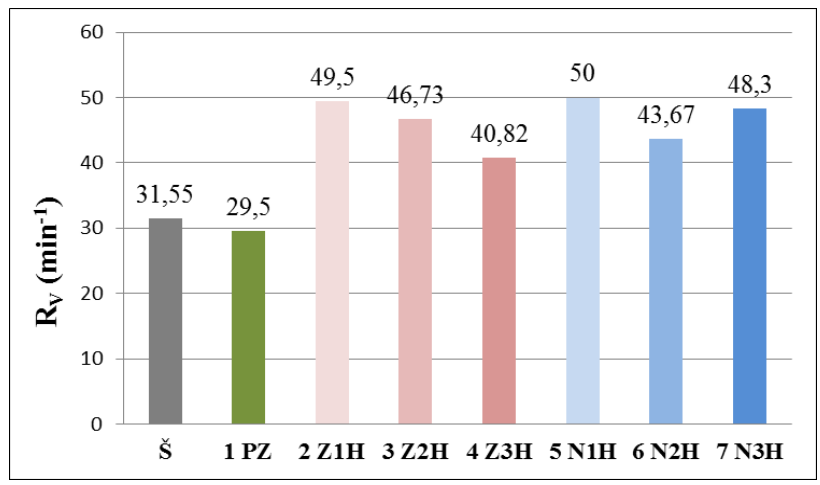

Fig. 9. Values of cure rate coefficient $R_{v}$ of rubber compounds

\subsection{Effect of additives on physical and mechanical properties of vulcanizates}

\subsubsection{Rubber compounds with alternative fillers based on glass waste}

The selected physical and mechanical properties (tensile strength, elongation at breakand hardness) were tested and evaluated. Resulting graphic images of these properties are shown in Figs. 10 - 11. From Fig. 10 it can be seen, that samples BK 2:1 and BKM 2:1 show the lower values of tensile strength. On the other side, samples of vulcanizates BKA 2:1 and BKE 2:1 show higher tensile strength values in comparison with vulcanizate sample BK 2:1 which was filled with unmodified alternative filler. Modification of alternative filler showed improvement in relation to evaluation of tensile strength. The highest value of tensile strength showed the BKA 2:1 sample which was filled with alternative filler modified with silane (3-Aminopropyl)triethoxysilane.



Fig. 10. Values of tensile strength of vulcanizates

Fig. 11 shows that blends samples BKA 2:1, BKE 2:1 and BKM 2:1, containing alternative fillers modified with silanes show an increase in hardness value in comparison with the rubber compound sample BK 2:1 filled with unmodified alternative filler. 


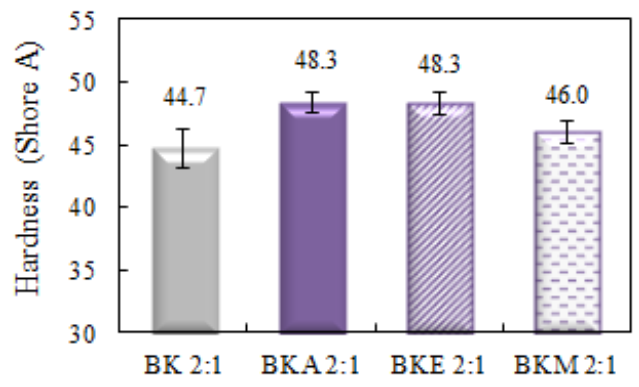

Compounds

Fig. 11. Values of hardness of vulcanizates

The increase of hardness is a manifestation of improving the interaction between the filler and the polymer matrix due to increased activity of the modified filler surface.

\subsubsection{Rubber compounds with alternative fillers based on clinoptilolite}

The selected physical and mechanical properties (Tensile strength, Elongation at break and Hardness) were tested and evaluated. The results from the measurements of physical and mechanical properties of prepared model vulcanizates are given in Table 5. From the obtained values it can be concluded, that modification of filler based on clinoptilolite showed improvement of tensile strength values. The greatest value of tensile strength achieved vulcanizate $2 \mathrm{Z} 1 \mathrm{H}$ with silanized filler that showed a slightly higher value of tensile strength than standard vulcanizate $\breve{S}$ with carbon black. It can be concluded that the modified filler based on clinoptilolite $2 \mathrm{Z} 1 \mathrm{H}$ and rubber matrix formed a stronger crosslinks network during vulcanization process than in standard vulcanizate $\breve{S}$. The lowest tensile strength value showed vulcanizate $1 \mathrm{PZ}$. It can be concluded that the silanization of clinoptilolite filler under various conditions had a positive effect on the results of tensile strength.

Table 5. Fillers content in prepared model rubber compounds (in phr) with the labeling of samples

\begin{tabular}{|c|c|c|c|c|c|c|}
\hline Vulcanizate & $\begin{array}{c}\text { Tensile strength } \\
\text { (MPa) }\end{array}$ & Sd & $\begin{array}{c}\text { Tensibility } \\
(\%)\end{array}$ & Sd & $\begin{array}{c}\text { Hardness } \\
\text { (IRHD) }\end{array}$ & Sd \\
\hline$\check{\mathbf{S}}$ & 19.17 & \pm 0.95 & 180.5 & \pm 17.08 & 79.4 & \pm 1.82 \\
\hline $1 P Z$ & 17.00 & \pm 0.93 & 301.4 & \pm 12.20 & 61.8 & \pm 2.17 \\
\hline $2 \mathrm{Z1H}$ & 19.35 & \pm 0.61 & 224.4 & \pm 4.56 & 64.4 & \pm 2.41 \\
\hline $3 \mathrm{Z2H}$ & 17.78 & \pm 0.87 & 212.6 & \pm 7.99 & 64.8 & \pm 0.84 \\
\hline $4 \mathrm{Z3H}$ & 17.46 & \pm 0.66 & 231.8 & \pm 4.38 & 65.4 & \pm 1.14 \\
\hline $5 \mathrm{N1H}$ & 17.10 & \pm 0.75 & 205.2 & \pm 10.89 & 66.0 & \pm 1.22 \\
\hline $6 \mathrm{N2H}$ & 17.75 & \pm 0.75 & 220.0 & \pm 3.39 & 64.0 & \pm 2.00 \\
\hline $7 \mathrm{N3H}$ & 17.53 & \pm 1.05 & 209.4 & \pm 3.13 & 66.8 & \pm 0.84 \\
\hline
\end{tabular}

The obtained values of elongation at break indicate, that higher values showed vulcanizate $1 \mathrm{PZ}$ with the addition of unmodified natural clinoptilolite.

Also vulcanizates with modified fillers 2-7 showed higher values of elongation at break compared to the vulcanizate with the standard filler. These results indicated that the vulcanizates containing the zeolite fillers silanized under the various conditions show a 
higher elasticity in comparison to standard vulcanizate, which can be utilized in applications where high elasticity of products is required.Based on the measured values of hardness it can be found that the hardness values decreased substantially by applying a zeolite fillers. It is clear that zeolite fillers slightly softens the rubber compounds. Vulcanizates containing silanized forms of clinoptilolite achieved higher hardness values compared to vulcanizate $1 \mathrm{PZ}$ with a natural clinoptilolite. From the above it can be concluded that the silanization had a positive effect on the increase of hardness values.

\subsection{Microstructural SEM analysis}

Microstructure of fillers and vulcanizates was studied using Scanning Electron Microscopy (SEM). For the determination of glass waste filler particles size (Fig. 12) were realized several measurements, which were based on applications $2 \mathrm{D}$ elements in an image from SEM. The measurements were carried out at 1000 times magnification of filler particles. The main purpose of the measurements was to determine the changes in particle size of the filler before and after modification using silanes.

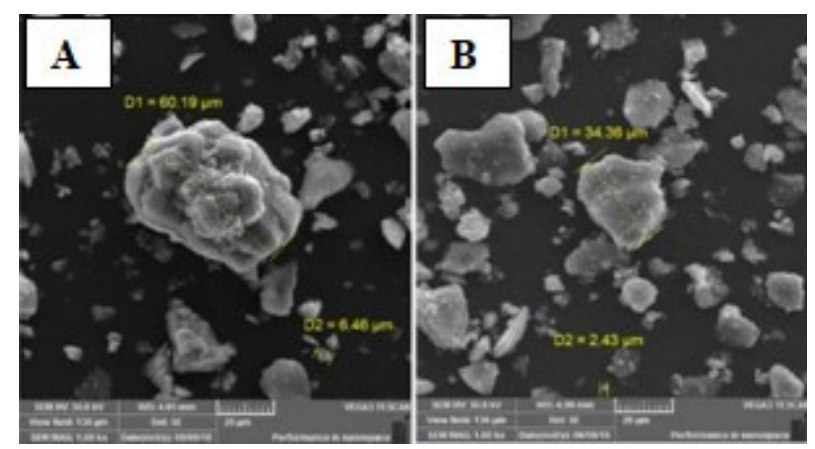

Fig. 12. Alternative filler (glass waste) particles size at $1000 \mathrm{x}$ magnification A - unmodified filler; B - filler after modification using (3-Aminopropyl)triethoxysilane

From Fig. 13 it can be seen, that the surface modification of the alternative filler using silane (3-Aminopropyl)triethoxysilane caused a reduction in the size of filler particles and thus an increase in the specific surface of alternative filler. The increase in specific surface contributed to increase in activity of filler particles and considerably improves the interaction between filler and polymer matrix (Fig. 13). 

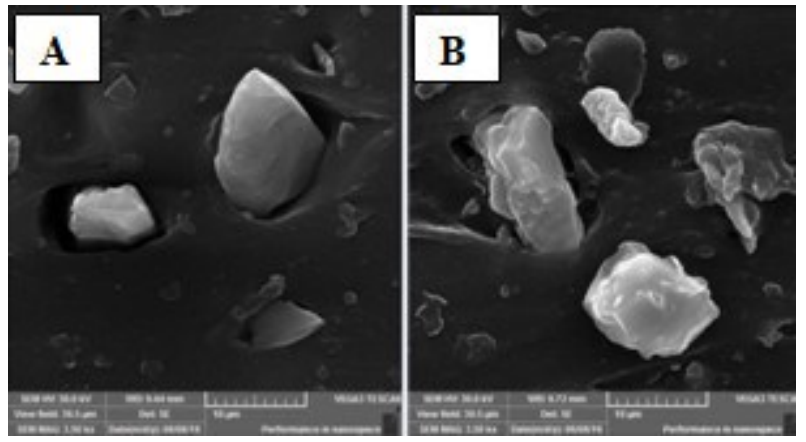

Fig. 13. Microstructure of vulcanizates with alternative filler (glass waste) $3500 \mathrm{x}$ magnification A - with unmodified filler; B - with filler after modification using (3-Aminopropyl)triethoxysilane

An improvement of interaction between polymer matrix and alternative filler (after modification using (3-Aminopropyl)triethoxysilane was manifested in images of microstructure of vulcanizates (Fig. 13). Thanks to detector that works in the SE mode it can be clearly seen and evaluated the incorporation of filler particles in the rubber matrix. Evaluation of the samples was carried out on the sample quarry at 3500 times magnification. The same trend of improvement of interaction between polymer matrix and modified alternative additivum was found in the case of alternative filler based on clinoptilolite (Fig. 14).

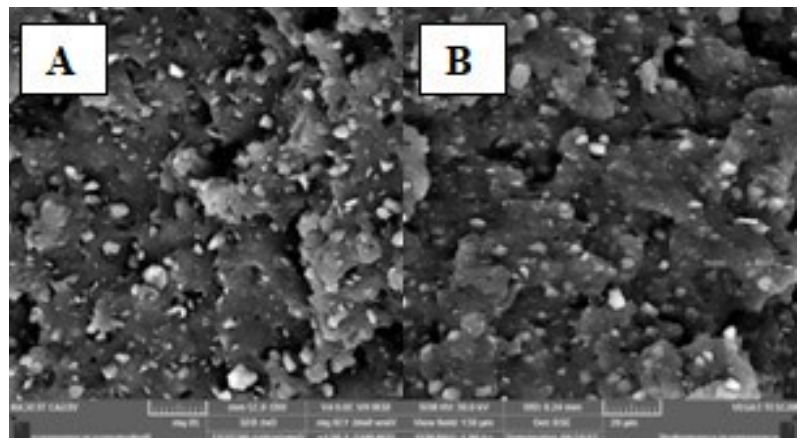

Fig. 14. Microstructure of vulcanizates with alternative filler (clinoptilolite) $1000 \mathrm{x}$ magnification A - with unmodified filler; B - with filler after modification using (3-Aminopropyl)triethoxysilane

\section{Conclusion}

According to the obtained results from the study of prepared modified alternative additives effect on rheology, curing characteristics of rubber compounds, physical and mechanical properties of vulcanizates and microstructural analysis of alternative filler and vulcanizates it was found an improvement of properties due to surface modification of alternative filler using silanes. In the case of alternative filler based on glass waste the best achieved properties showed sample BKA 2:1 which was filled with carbon black and alternative filler modified using (3-Aminopropyl)triethoxysilane in the ratio of fillers $2: 1$.

In the case of mineral alternative filler based on clinoptilolite the positive influence of silanization of clinoptilolite filler is considerable and the use of silane APTES showed a 
positive effect on the activity of all components in the rubber blends with the addition of modified zeolite filler.

This work was supported by the projects: VEGA No. 1/0589/17, VEGA No. 1/0649/17, KEGA 008 TnUAD-4/2017 and resulted from the project "Center for quality testing and diagnostics of materials", ITMS code 26210120046 relating to the Operational Program Research and Development funded from European Fund of Regional Development

\section{References}

1. E. P. Giannelis, Polymer layered silicate nanocomposites. Adv. Mater. 8, 29-35 (1996)

2. E. P. Giannelis, Polymer-layered silicate nanocomposites: synthesis, properties and applications. Appl. Organomet. Chem. 12, 675-680 (1998)

3. L. Domka, A. Malicka, N. Stachowiak, Production and structural investigation of polyethylene composites with modified kaolin. Acta physica polonica A114, 413-420 (2008)

4. G. Wypych, Handbook of fillers. (ChemTec publishing, Toronto, 1999)

5. J. C. Dai, J. T. Haung, Surface modification of clays and clay-rubber composite. Appl. Clay Sci. 15, 51-65 (1999)

6. G. Kakali , T. Perraki, S.Tsivilis, E. Badogiannis, Thermal treatment of kaolin: The effect of mineralogy on the pozzolanic activity. Appl. Clay Sci. 20, 73-80 (2001)

7. H. He, Q. Tao, P. Zhu, W. Shen, S. Yang, Silylation of clay mineral surfaces. Appl. Clay Sci. 71, 15-20 (2013)

8. S. Letaief, I. K. Tonle, T, Diaco, C. Detellier, Nanohybrid materials from interlayer functionalization of kaolinite. Application to the electrochemical preconcentration of cyanide. Appl. Clay Sci. 42, 95-101 (2008)

9. E. Moretti, L. Storaro, G. Chessa, A. Talon, E. Callone, K. J. Mueller, F. Enrichi, M. Lenarda, Stepwise dansyl grafting on the kaolinite interlayer surface. J of Coll. and Interf.Sci. 375, 112-117 (2012)

10. Y. Yuan, H. Chen, J. Lin, Y. Ji, Surface modification of calcined kaolin with toluene diisocyanate based on high energy ball milling. Appl. Surf. Sci. 284, 214-221 (2013)

11. G. Wypych, Handbook of Fillers. (ChemTec Publishing, Toronto, 2010)

12. S. Mihara, Reactive Processing of Silica-Reinforced Tire Rubber. Ph.D thesis, University of Twente, Enschede, the Netherlands, ISBN: 978-90-365-2839-9 (2009)

13. D. Ondrušová, M. Pajtášová, Rubber Components and their Influence on Rubber Properties and Environmental Aspects of Production. Towarzystwo Słowaków w Polsce, 166 p., ISBN 978-83-7490-385-1 (2011)

14. J. Vavro Jr., J. Vavro, P. Kováčiková, P. Kopas, M. Handrik, Simulation and analysis of defect distribution in passenger car tire under dynamic loading. Applied mechanics and materials. 611, 544-547 (2014)

15. STN 62 1416, Determination of vulcanization characteristics on vulcameter.

16. STN ISO 37, Determination of tensile stress-strain properties.

17. ISO 48, Determination of hardness. 